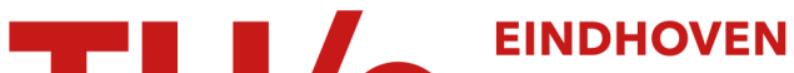 \\ UNIVERSITY OF \\ TECHNOLOGY
}

\section{Conjoint models of tourist portfolio choice : theory and illustration}

\section{Citation for published version (APA):}

Dellaert, B. G. C., Borgers, A. W. J., \& Timmermans, H. J. P. (1997). Conjoint models of tourist portfolio choice : theory and illustration. Leisure Sciences, 19(1), 31-58. https://doi.org/10.1080/01490409709512238

DOI:

10.1080/01490409709512238

Document status and date:

Published: 01/01/1997

\section{Document Version:}

Publisher's PDF, also known as Version of Record (includes final page, issue and volume numbers)

\section{Please check the document version of this publication:}

- A submitted manuscript is the version of the article upon submission and before peer-review. There can be important differences between the submitted version and the official published version of record. People interested in the research are advised to contact the author for the final version of the publication, or visit the $\mathrm{DOI}$ to the publisher's website.

- The final author version and the galley proof are versions of the publication after peer review.

- The final published version features the final layout of the paper including the volume, issue and page numbers.

Link to publication

\section{General rights}

Copyright and moral rights for the publications made accessible in the public portal are retained by the authors and/or other copyright owners and it is a condition of accessing publications that users recognise and abide by the legal requirements associated with these rights.

- Users may download and print one copy of any publication from the public portal for the purpose of private study or research.

- You may not further distribute the material or use it for any profit-making activity or commercial gain

- You may freely distribute the URL identifying the publication in the public portal.

If the publication is distributed under the terms of Article $25 \mathrm{fa}$ of the Dutch Copyright Act, indicated by the "Taverne" license above, please follow below link for the End User Agreement:

www.tue.nl/taverne

Take down policy

If you believe that this document breaches copyright please contact us at:

openaccess@tue.nl

providing details and we will investigate your claim. 


\title{
Conjoint Models of Tourist Portfolio Choice: Theory and Illustration
}

\author{
BENEDICT G. C. DELLAERT
}

Department of Marketing

University of Sydney

Sydney, Australia

\section{ALOYS W. J. BORGERS}

Faculty of Architecture, Building, and Planning

Eindhoven University of Technology

Eindhoven, The Netherlands

\section{HARRY J. P. TIMMERMANS}

Faculty of Architecture, Building, and Planning

Eindhoven University of Technology

Eindhoven, The Netherlands

and

Carthy Chair of Marketing,

Faculty of Business, University of Alberta

Edmonton, Alberta, Canada

This article develops and tests a conjoint choice model of portfolio choice behavior. It shows how experimental design principles and discrete choice model specifications can be used to model the choice of travel portfolios. Design strategies, model formulations, and estimation methods are discussed and illustrated through use of Dutch iourists' choices of destination and transportation for short city breaks as an example. Findings support the suggested methodology and indicate that the nested logit model is most appropriate in the tested application.

Keywords conjoint models, experimental design, logit, pacǩaging, portfolio choice, probit

\section{Problem Context}

The leisure and tourism industry has experienced substantial change recently. As in many other industries, strategic alliances and mergers have had a dramatic impact on competitive strategies, at both the national and the international level. This development has allowed companies to compete more effectively at a global scale, as is reflected partly in new products and services. Whereas previously different companies and business offered

Received 28 November 1995; accepted 12 September 1996.

This research was funded in part by a grant from the Tourism Department of the Dutch Ministry of Economic Affairs.

Address correspondence to Benedict G. C. Dellaert, Senior Lecturer, Department of Marketing, University of Sydney, Sydney, NSW 2006, Australia.E-mail:benedictd@bullwinkle.econ.su.02.au 
different products and services in the marketing channel, there is now an increased tendency toward vertical integration, resulting in the offering, distribution, and marketing of a variety of tourist packages as opposed to more or less unpackaged products and services that either travel agents or consumers had to combine (Ryan, 1991; Sheldon, 1986; Sheldon \& Mak, 1987). A good overview of recent research in the area was made by Hooper (1994), who analyzed the phenomena from a microeconomic perspective. Recently, Dellaert et al. (1996) and Fesenmaier (1995) also have proposed conceptual frameworks to structure the analysis of tourists' choices of different components of travel portfolios. Both distinguish the following primary components in travel decisions, that is, components of travel that are typically chosen before rather than during the trip: (a) destination, (b) accommodation, (c) travel companions, (d) travel mode, (e) departure date, and (f) duration. Potentially, choices between all or a combination of these components can be packaged by firms operating in the travel industry. Regardless of industry packaging, all components are essential in the tourist travel choice process, and tourists need to make trade-offs between different components in the travel portfolios.

The increased focus on packaging offers new challenges to leisure science. Traditionally, the study of consumer demand for leisure and tourist products and services has received major attention. Various theories and models, such as the multinomial logit and conjoint preference and choice models (e.g., Carmichael, 1993; Haider \& Ewing, 1990; Lieber \& Fesenmaier, 1984; Louviere \& Timmermans, 1990, 1992; Morey, Shaw \& Rowe, 1991; Peterson, Dwyer \& Darragh, 1983; Stynes \& Peterson, 1984; Williams, 1979) have been developed over the years to measure and predict consumer preferences and choice behavior and to support product development and marketing decision making. These studies allowed researchers to identify the relative importance of the attributes that influence consumer choice behavior and to predict the potential market share of new products and services, thereby offering a tool to assess the feasibility and impact of marketing strategies and to identify market segments for those new products and services. Other studies focused on the constraints consumers face (e.g., Henderson \& Bialeschki, 1991; Jackson, 1988). Typically, however, the studies to date have examined consumer response to single products and services. For example, many studies have addressed the problem of destination choice (e.g., Crompton, 1992; Mansfeld, 1992; Woodside \& Lysonski, 1989; Woodside, Pearce, \& Wallo, 1989). The results of those studies may provide useful information to managers and increase our understanding of the relative importance of the factors influencing tourists' destination choice. However, they assume either implicitly or explicitly that destination choices are made independently from, for instance, transport mode choice and choice of activity. Consequently, in the context of the assessment of alternative package offerings, the findings of such studies are limited at best or may even be misleading if the choice of destination happens to be systematically related to the choice of other components of the package. Moreover, because of their limited scope, such studies and models do not provide any information regarding the ways in which the various components of the package interact in influencing consumer preferences and choice behavior. Conventional discrete choice and conjoint preference models developed in leisure science do not allow one to draw conclusions about potential synergies or ineffectiveness in consumers' preferences for and choices among tourist packages, because these models typically address the problem of single choices as opposed to portfolio or interrelated choice behavior ${ }^{1}$. In the portfolio case it is a nontrivial question

\footnotetext{
'In this paper we will use the term porffolio choice to indicate tourists' choices of combinations of several travel components. In this term we include both choices of prepackaged travel components and tourists' independent choices of multiple travel components.
} 
whether consumers evaluate travel portfolios in a single simultaneous choice or whether each component is evaluated separately.

The aim and contribution of this study to leisure science is to develop and test a conjoint-based choice model of package or portfolio choice that allows us to model and test possible structures of tourist portfolio choice processes. Conjoint choice models assume that one can observe consumer choices for hypothetical choice alternatives, described in terms of attribute profiles, to derive a preference function and a choice model simultaneously (e.g., Louviere \& Timmermans, 1990). Creating such models involves constructing an experimental design that varies the attributes of interest according to the principles of the design of statistical experiments so that the riecessary and -sufficient conditions to estimate the choice model of interest are satisfied. Hence, the development of a conjoint model of portfolio choice requires (a) the specification of a choice model that allows one to examine and estimate the influence of the various components of the portfolio choice and (b) an appropriate design strategy to result in an experimental design that allows one to estimate the aforementioned model specification.

Our study of portfolio choice in leisure science is consistent with a recent stream of research in the geography, marketing, planning, and transportation literatures that raises the issues of portfolio choice and multipurpose traveling. In marketing, researchers specifically have analyzed combined choices among assortments of goods (e.g., Harlam \& Lodish, 1995; Kahn \& Lehman, 1991). In the spatial sciences, choice models for multipurpose trip chains have been developed for retail store choice (e.g., Arentze, Borgers, \& Timmermans, 1993; Ingene \& Ghosh, 1990; Kitamura, 1984) and for the choice of shopping centers and shops within centers (e.g., Ahn \& Ghosh, 1989). To the best of our knowledge, however, conjoint models for portfolio choices are rare in these fields of study and leisure science alike.

We present and compare four different model structures and research their ability to predict tourists' portfolio choices of combined destination and transportation components. Results of an application of these models to Dutch tourists' choices of short city breaks to urban destinations in Belgium, Germany, and the Netherlands are presented. To this effect, the article is organized as follows. First, we discuss the various model specifications, design strategies, and estimations of the portfolio models. In the following section, we provide further details on the study area and the data collection. This section is followed by a presentation of the analyses and the research findings. Finally, we draw some conclusions and discuss our findings.

\section{Issues of Model Formulation, Experimental Design, and Estimation}

\section{Conceptual Considerations}

Consider the problem of a choice among a set of portfolio choice alternatives, where a portfolio choice alternative is defined as an alternative consisting of interrelated constituent components. For example, tourists' portfolio choices may be choices among tour operator packages including a travel mode, a destination, and accommodation; choices between day excursion programs including travel, visits to attractions, and meals; or choices between various travel routes and stops in a self-drive tour through a beautiful region. Assume that each of the components in the portfolio can be described as a multiattribute profile and that, consequently, the portfolio can be described as a combination of these multiattribute profiles. Assume that individual choice behavior is influenced by the set of identified attributes representing the multiattribute profile and that 
individuals view and evaluate each profile attribute as a function of a set of goals and objectives, various constraints, and their filtered and possibly imperfect perceptions and cognitions of the alternatives available in their environment, which define their choice sets. This valuation process results in a preference or utility value for each portfolio component. Assume that these constituent utilities are processed and integrated to arrive at some overall preference/utility or choice according to some integration/choice rule. The question, then, is how to specify the way in which the attribute evaluations are processed to arrive at each portfolio component's utility and how to represent the integration of these constituent utilities to predict overall portfolio preference or choice.

If we addressed this problem using conventional approaches, two strategies would need to be considered. The first would be to treat portfolio choice in the traditional way, making no explicit distinction between the choices of the various components of the portfolio choice of interest. The conceptual difficulty with this approach, however, would be that one implicitly assumes that individuals process all attributes simultaneously, that is, that in the portfolio choice all components are evaluated in one simultaneous process and no possibility exists for variations in choice processes for different components. Moreover, an operational difficulty of this approach would be that the number of influential attributes is likely to become very large, especially if the portfolio has many components. Consequently, it probably would be virtually impossible to construct experimental designs that would satisfy the conditions to estimate the choice model of interest, and moreover, task demands for respondents would be overwhelming.

Alternatively, one could conceptualize the portfolio choice problem similarly to the hierarchical information integration process and estimate hierarchical conjoint choice models (e.g., Louviere \& Timmermans, 1990, 1992). This process would involve conceptualizing the portfolio components analogously to decision constructs in hierarchical information integration. Thus, one would assume that individuals evaluating portfolios group the attributes of interest into their portfolio components, construct an evaluation for each component, and then integrate their preferences for or evaluations of these components into an overall preference or choice. The measurement of this assumed process would involve either the design of separate subexperiments to measure the construct/component evaluations and a separate bridging experiment to measure the contributions of these construct/components evaluations to final choice as in conventional hierarchical information integration, or the use of integrated choice experiments (Oppewal, Louviere, \& Timmermans, 1994) to replace the bridging experiment. While the latter approach in particular has some appeal, because it would allow one to estimate the interaction between attributes and decision constructs, it might still be too limited to represent adequately and predict portfolio choice behavior; in common with all other conjoint approaches, it would be restricted to single simultaneous choice structures and would not allow one to test conditional structures. This is not to say that portfolio choices are best conceptualizếd as conditional choices (note that we deliberately use a more neutral terminology in our conceptual considerations above), but one would ideally use an approach that allows one to test various processing structures, both simultaneous and conditional.

In common with the above approaches, we assume that individuals choose the portfolio alternative that provides the highest utility to them. In the present study, the choice problem of interest concerns the choice of a destination, $D_{j}$, from a set of destinations $J$ (Component 1) and a transportation mode, $T_{k}$, from a set of transportation modes $K$ (Component 2). Consistently with random utility theory, we assume that tourists base their choices on an evaluation of destination and transportation component attributes, the utility 
of which consists of structural parts $V_{D}$ and $V_{T}$, related to destination and transportation, respectively, which are constant over time and common to all tourists, and a stochastic part $\varepsilon$, the error term, that captures disturbances in utility because of taste variations within and between tourists as well as measurement errors (Ben-Akiva \& Lerman, 1985; McFadden, 1981). For example, the structural component of the utility function can represent a person's structural preference for a certain transportation mode (e.g., car). However, the person may sometimes choose to travel by train because of circumstantial factors not included in the model (e.g., if the car is being serviced). This unexplained variance in choice is captured by including the stochastic part in the model. Similarly, when aggregate models are estimated, variations in preferences between individual consumers are captured in the stochastic component. Depending on the assumptions one is willing to make with regard to tourists' choice processes and the structure of the stochastic part of the utility, different model structures can be generated.

In this paper we focus specifically on the relationship between the stochastic part in portfolio utility functions and the components from which the portfolios are constructed. This relationship is discussed in the next section.

\section{Role of the Stochastic Component}

Traditionally, tourist choice research has focused heavily on the structural component in tourists' utility functions, and researchers have looked for new ways to incorporate more diverse structural effects in models describing tourist choice processes. However, many of the recent developments in consumer choice modeling have taken place in the area of the stochastic structures associated with the structural components (e.g., Chintagunta, 1992; McFadden, 1989). Attention has been paid to modeling possible unobserved commonalities between alternatives (e.g., because of shared product characteristics not included in the model). This is an area that is especially relevant to portfolio choice modeling, because it can often be expected that different components in a portfolio will share different unobserved variables. For example, it can be expected that two transportation-destination portfolios that share the same destination component will also share the same unobserved characteristics of that destination and, consequently, the part of the stochastic component related to that destination. This assumption implies that the error terms of two portfolios that share the same destination components are not independent.

If in portfolio choice models, similar assumptions were made with regard to the stochastic component to those that are made in the simple multinomial logit (MNL) model for single choices, then the total error terms over the sets of components that make up a portfolio would be assumed to be independently and identically distributed (IID) according to a Gumbel distribution (Ben-Akiva \& Lerman, 1985, p. 278).

However, a serious objection to the assumption of IID error terms is that the separate components that make up portfolio alternatives are likely each to have their own separate stochastic component. In that case, portfolios that share part of their alternatives will also share part of their error terms, leading to covariances between the overall error terms of portfolio altematives and therefore to violations of the IID assumption. The utility functions for combined and conditional portfolio choices for a portfolio of destination and transportation, including separate error terms are expressed in Formula 1. The variancecovariance structure of the utilities that follows from this structure is expressed in Formulas 2 to 4. 


$$
\begin{aligned}
& U_{D j T k}=V_{D j}+V_{T k}+V_{D j T k}+\varepsilon_{D j}+\varepsilon_{T k}+\varepsilon_{D j T k} \\
& U_{T k \mid D j}=V_{T k}+V_{D j T k}+\varepsilon_{T k}+\varepsilon_{D j T k} \\
& U_{D j T k}=V_{D j}+V_{D j T k}+\varepsilon_{D j}+\varepsilon_{D j T k}
\end{aligned}
$$

where: $U_{D j T k}$ is the total utility of the combination of alternatives $D_{j}$ and $T_{k}$,

$J$ is the total number of destinations $D_{j}$,

$K$ is the total number of transportation modes $T_{k}$

$U_{T k 1 D j}$ is the utility of alternative $T_{k}$ given $D_{j}$,

$U_{D j \mid T k}$ is the utility of alternative $D_{j}$ given $T_{k}$,

$V_{D_{j}}$ is the structural utility of $D_{j}$,

$V_{T k}$ is the structural utility of $T_{k}$,

$V_{D j T k}$ is the structural utility of the interaction between $D_{j}$ and $T_{k}$, and

$\varepsilon_{D j}, \varepsilon_{T k}$, and $\varepsilon_{D j T k}$ are stochastic components or error terms over the main effects for the two components and their interaction.

The underlying variance-covariance matrix of the error terms in the combined destination transportation choice is expressed as:

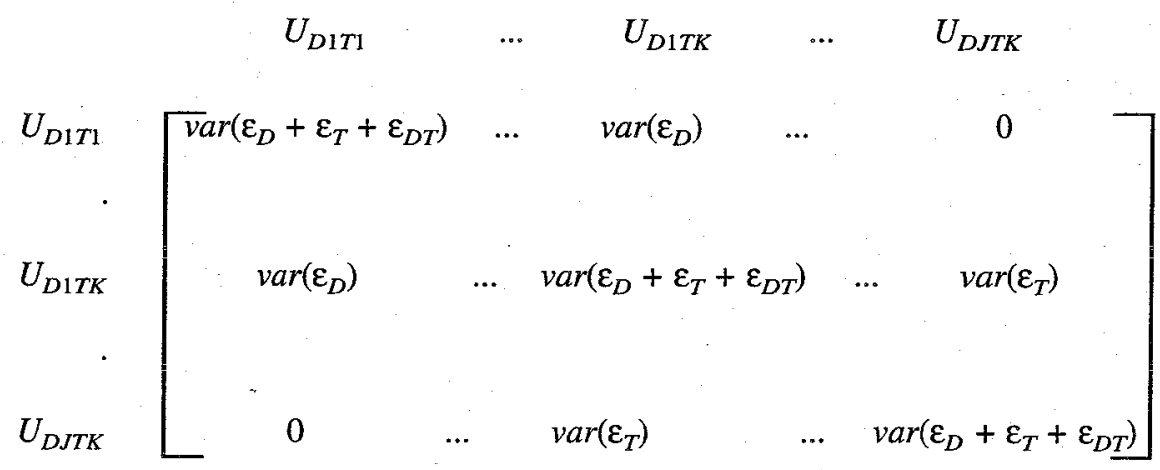

where $\varepsilon_{D 1}=\varepsilon_{D J}=\varepsilon_{D}, \varepsilon_{T 1}=\varepsilon_{T K}=\varepsilon_{T}$, and $\varepsilon_{D 1 T 1}=\varepsilon_{D 1 T K}=\varepsilon_{D J T K}=\varepsilon_{D T}$, and all other elements are defined as before. The covariance in this matrix accounts for the fact that certain portfolios share common components. Because the stochastic components related to each component are assumed to be $\mathrm{ID}$, the covariances for alternatives that share a common component (e.g., $T_{k}$ ) can be expressed as follows (Ben-Akiva \& Lerman, 1985, p. 286):

$$
\begin{aligned}
& \operatorname{cov}\left(\varepsilon_{D j}+\varepsilon_{T k}+\varepsilon_{D j T k}, \varepsilon_{D j^{\prime}}+\varepsilon_{T k}+\varepsilon_{D j^{\prime} T k}\right) \\
& =\operatorname{cov}\left(\varepsilon_{T k}, \varepsilon_{T k}\right) \\
& =\operatorname{var}\left(\varepsilon_{T k}\right)
\end{aligned}
$$

where $j^{\prime} \varepsilon J, j^{\prime} \neq j$, and all other elements are defined as before. This is a very relevant feature, because it allows us to translate observed differences in variance between com- 
bined and conditional portfolio choices into the underlying variance-covariance matrix for the portfolio choices. The variance-covariance matrix for the conditional choice is:

$$
U_{T 1 D 1}\left[\begin{array}{ccc}
U_{T 1 \mid D 1} & \cdots & U_{T K 1 D 1} \\
U_{T K 1 D 1} & \cdots & 0 \\
0 & \ldots & \operatorname{var}\left(\varepsilon_{T}+\varepsilon_{D T}\right)
\end{array}\right]
$$

where all elements are defined as before.

An important issue in categorical choice models such as the logit model is that differences in variance between choice situations, such as those that occur in the above variance-covariance structures, directly lead to differences in parameter estimates for these choice situations, even if the underlying structural utilities are the same, because there is a direct relationship between the variance of the error term and the scale of the parameter estimates. In logit models, this relationship is expressed as: $\operatorname{var}(\varepsilon)=\pi^{2} / 6 \mu^{2}$, where $\varepsilon$ is the error component of the utility function and $\mu$ is a parameter that determines the scale of the Gumbel distribution (Ben-Akiva \& Lerman, 1985, p. 105). A similar relationship between variance and scale exists in all categorical choice models including the probit model.

Generally, in categorical choice models the estimated parameter values for the structural utilities $V$ are confounded with the scale parameter $\mu$, and only the product of $\mu$ and $V$ is estimated. In the estimation process the scale parameter $\mu$ is therefore generally set to an arbitrarily selected convenient value (e.g., 1 in the simple MNL model), and the structural parameters are estimated in relation to this value (Beñ-Akiva \& Lerman, 1985 p. 71). As a consequence, estimations made in choice situations with identical structural parameter values but with different underlying scale parameters do not lead to identical parameter estimates. Thus, for estimations made in choice situations with different error terms the parameter values are necessarily different.

If, for example, there exist two choice situations with error terms $\varepsilon_{1}$ and $\varepsilon_{2}$ and scale values $\mu_{1}$ and $\mu_{2}$, the assumption of equally distributed error terms $\varepsilon_{T}$ may lead to biases in the estimated parameter values. Swait and Louviere (1993) have shown that the Maximum Likelihood Estimator (MLE) necessarily overpredicts for the choice situations with the larger variance (i.e., smaller $\mu$ ) and underpredicts for the situations with the smaller variance (i.e., larger $\mu$ ), where the degree of over- and underprediction depends on the number of observations made in each choice situation. This observation is especially relevant to experimental design techniques used in conjoint choice modeling. We will discuss this issue more in depth in a later section, when we introduce the proposed design approach.

Finally, it should be noted that much recent research in marketing also has focused on modeling differences in unobserved variance between respondents rather than between alternatives. For example, Chintagunta and Honore (1996) and Gonul and Srinivasan (1993) developed choice models that incorporate corrections for unobserved heterogeneity across consumers. In our study we take the so-calied average individual approach, which effectively dictates that we estimate models on the aggregate response across all respondents. In this approach, the error term captures the unobserved differences between respondents, and the structural parameters represent the average utilities across respondents. This approach would be somewhat troublesome in situations when market segments exist 
with clearly different and opposite preferences for certain attributes, because the estimated structural parameter would incorrectly suggest that these attributes do not influence respondent choice. However, in conjoint experiments respondents are randomized across choice sets, and, furthermore, the occurrence of different attribute levels is balanced by the design. Even though the heterogeneity effect may still bias the estimates downward, it should do so systematically across all choice situations. Therefore, its effect can be expected not to interfere with the estimates for portfolio component-based variance differences.

\section{Model Formulation}

In this section we describe the outline and background of four model specifications for consumer choice processes that previously have been proposed in the choice modeling literature and compare them in terms of their suitability to capture tourists' portfolio choice processes. Although not all of these approaches were originally specified from a portfolio choice perspective, they have been applied as such and can be considered as competing options for modeling tourists' portfolio choices. In our study the approaches are tested and compared on their suitability to model tourists' transportation-destination portfolio choices. The formal definition of the approaches is given in the next section.

The first structure that is potentially suitable to describe tourists' portfolio choices is the joint logit model. This model is mathematically identical to the simple MNL model, which is the most commonly applied model in conjoint choice analysis (e.g., Haider \& Ewing, 1990; Louviere \& Timmermans, 1990; Oppewal et al. 1994). The joint logit model differs from the simple MNL model in that it allows one to introduce attributes from different portfolio components simultaneously in the model structure, whereas the simple MNL model typically is based on choices of single components only. In the joint logit model it is assumed that

(a) The value of the structural components in the utility function are identical for tourists' combined and conditional destination and transportation choices (for example, the structural utility of a transportation mode does not differ in a combined destination and transportation choice and a choice of transportation conditional on a given destination), and

(b) the stochastic parts of the utility function for all portfolios follow IID Gumbel distributions.

This latter assumption implies that all portfolios are evaluated in an identical choice process and that separate components of the portfolio are evaluated simultaneously.

A second approach to modeling portfolio choices is the nested logit model (e.g., Ahn \& Ghosh, 1989; Ben-Akiva \& Lerman, 1985). Nested logit models represent a first step toward the estimation of a full variance-covariance matrix of the stochastic components in the random utility model, which allows one to test certain variance-covariance structures in the unobserved stochastic components that could exist because of, for example, different sequences in the consumer choice process or unobserved similarities between alternatives. Nested logit models still assume that the underlying parameters of the portfolio components are identical in combined and conditional choices, but allow the stochastic element in the portfolios' utility functions to be hierarchically clustered in such a way that differences between the stochastic components of portfolio alternatives that share certain components are smaller than the differences between those of portfolio alternatives that do not share components. The model allows for the stochastic parts of portfolios 
within branches of the hierarchical structure to have common elements related to the shared components. Although the hierarchical structure does not necessarily coincide with a sequential decision-making process-essentially, it is only a description of the variancecovariance structure in the model-it often can be understood as such intuitively. The component that is "nested" under the other component can be seen intuitively as being chosen later in the tourist choice process. Specifically, in the nested logit model it is assumed that

(a) the values of structural components in the utility functions are identical for tourists' combined and conditional destination and transportation portfolio choices, and

(b) stochastic components in each of the branches of the hierarchical structure are identically Gumbel distributed. It is furthermore assumed that components of the error term specifically related to different levels in the hierarchical tree structure are independently distributed. Together, these two assumptions imply that covariances between the error terms over the utility of one of the components in the two component portfolio alternatives are equal to zero.

A third possible approach to portfolio choice modeling is represented by the probit model (e.g., Ben-Akiva \& Lerman, 1985; Daganzo, 1979). The probit model uses the normal distribution to represent the covariance structure in the model better, and it recognizes the fact that all components in the portfolio choice can share certain component specific unobserved variables. An important advantage of the normal distribution for modeling dependencies between stochastic terms is that covariances and variances between error terms can be modeled without the need to change the model's functional expression. Independent and identical error terms are a special case of the general model in which all error terms in the utility function have different interdependencies. In the probit model it is assumed that

(a) the structural parameter values in the combined and conditional portfolio choices are identical, and

(b) there exist covariances between the error terms of different portfolios' utility functions if these porifolios share one or more components.

It is important to note that, in contrast to other probit models that have been applied in planning and marketing (e.g., Bunch \& Kitamura, 1989; Chintagunta, 1992), the model we propose represents a restricted version of the probit model. In our approach we apply the probit model to describe the specific type of covariances that occur as a result of common components in different portfolio alternatives. Other possible causes of covariances are not dealt with within the model structure. In the presented approach this restriction is justifiable, because in conjoint choice analyses choice set composition is controlled for in the experimental design. Consequently, it can be expected that heterogeneity among respondents is not systematically related to parameter estimates, because the researcher randomizes the hypothetical choice sets across respondents.

In the fourth approach, choices for different combinations of components in the portfolio are modelled as essentially different choice processes. In this case, separate parameters are estimated for the combined destination and transportation choice and for both the conditional transportation and conditional destination choices. We call this the component-based logit model. In this model it is assumed that

(a) choices for different combinations of components in portfolios are regarded as essentially different choice processes, and 
Table 1

Assumptions in the proposed portfolio model structures of destination and transportation choice

\begin{tabular}{|c|c|c|}
\hline \multirow[b]{2}{*}{ Portfolio model structure } & \multicolumn{2}{|c|}{$\begin{array}{l}\text { Assumed properties of choices for different } \\
\text { component combinations }\end{array}$} \\
\hline & $\begin{array}{c}\text { Identical structural } \\
\text { utilities } V\end{array}$ & $\begin{array}{l}\text { Identical stochastic } \\
\text { components } \varepsilon\end{array}$ \\
\hline Joint logit model & yes & yes \\
\hline $\begin{array}{l}\text { Nested logit model } \\
\text { (destination in nest) }\end{array}$ & yes & $\begin{array}{l}\text { only for transportation } \\
\text { choice }\end{array}$ \\
\hline $\begin{array}{l}\text { Nested logic model } \\
\text { (transportation in nest) }\end{array}$ & yes & $\begin{array}{l}\text { only for destination } \\
\text { choice }\end{array}$ \\
\hline Probit model & yes & no \\
\hline Component-based logit model & no & no \\
\hline
\end{tabular}

(b) the stochastic components of tourists' utility functions for these choice situations are assumed to differ as well.

An example of a similar approach is the one described by Gupta (1988), who studied consumer purchase incidence and brand choice.

Table 1 summarizes the four proposed approaches and the different assumptions that are made in each of the model structures with regard to both the structural and stochastic parts in tourists' utility functions for portfolios of destination and transportation components.

In the next section we describe the four modeling approaches formally. Following that section, we discuss an experimental design strategy that supports estimation of the model structures and an approach to estimating and comparing the models.

\section{Formal Model Definition}

Joint logit model. Let $J$ be a set of tourism destinations $D_{j}$, and $K$ a set of transportation modes $T_{k}$. Let $U_{D j T k}$ be the overall utility of portfolio alternative $D_{j} T_{k}, V_{D j}$ the structural utility of destination $b_{j}, V_{T k}$ the structural utility of transportation mode $T_{k}, V_{D j T k}$ the structural utility of the interaction between destination $D_{j}$ and transportation mode $T_{K}$, and $\varepsilon_{D j T k}$ the error term on the utility of portfolio alternative $D_{j} T_{k}$. Assume that all error terms $\varepsilon_{D j T k}$ are independently and identically distributed according to a Gumbel distribution with mode 0 and scale parameter $\mu$. Assuming that tourists are maximizing their utility, the utility of portfolio alternative $D_{j} T_{k}$ and the probability that it will be selected can be expressed as

$$
\begin{gathered}
U_{D j T k}=V_{D j}+V_{T k}+V_{D j T k}+\varepsilon_{D j T k} \\
P\left(D_{j} T_{k}\right)=\frac{\exp \left(V_{D j}+V_{T k}+V_{D j T k}\right)}{\sum_{j^{\prime} \varepsilon \delta} \sum_{k^{\prime} \varepsilon K} \exp \left(V_{D j^{\prime}}+V_{T k^{\prime}}+V_{D j^{\prime} T k^{\prime}}\right)}
\end{gathered}
$$


and the utility of transportation mode $T_{k}$ given the choice of destination $D_{j}$ and its probability are expressed as

$$
\begin{gathered}
U_{T k \mid D j}=V_{T k}+V_{D j T k}+\varepsilon_{D j T k} \\
P\left(T_{k} \mid D_{j}\right)=\frac{\exp \left(V_{T k}+V_{D j T k}\right)}{\sum_{k^{\prime} \varepsilon K} \exp \left(V_{T k^{\prime}}+V_{D j^{\prime} T k^{\prime}}\right)}
\end{gathered}
$$

Nested logit model: Let all elements be defined as before. Let $P\left(\Phi_{j}\right)$ be the probability that a combination including $D_{j}$ is chosen from the set of all combinations $D$ and $T, P\left(T_{k} D_{j}\right)$ the probability that alternative $D_{j} T_{k}$ is chosen from the $K$ alternatives in nest $D_{j}, \mu^{h i g h}$ and $\mu^{\text {low }}$ the scaling factors for the higher and the lower level, the "low" one of which is arbitrarily set to 1 so that the estimation of the other represents the ratio of the two scales. $V_{\text {nest }}$ is the inclusive value of the nest and represents the expected maximum utility of the components in the nest, and $\varepsilon_{D j}$ and $\varepsilon_{D j T k}$ respectively are error terms associated with the utility of destination $D_{j}$ and the unique combination $D_{j} T_{k}$. Assume that all error terms $\varepsilon_{D j T k}$ follow IID Gumbel distributions with mode 0 and scale parameter $\mu^{\text {low }}$, that all $\varepsilon_{D_{j}}$ are independent, and that all $\varepsilon_{D j}+\varepsilon_{D j T k}$ are identically Gumbel distributed, with mode 0 and scale parameter $\mu^{\text {high }}$. Then, the following equations describe a nested logit model in which destination is hierarchically structured over transportation:

$$
\begin{aligned}
& U_{D j T k}=V_{D j}+V_{T k}+V_{D j T k}+\varepsilon_{D j}+\varepsilon_{D j T k} \\
& V_{n e s t}=\frac{1}{\mu^{l o w}} \ln \sum_{k \varepsilon K} \exp \left[\left(V_{T k}+V_{D j T k}\right) \mu^{l o w}\right] \\
& P\left(D_{j}\right)=P\left(\max _{K}\left(U_{D j T k}\right)>\max _{K}\left(U_{D j^{\prime} T k}\right) ; \forall j^{\prime} \varepsilon J ; D_{j^{\prime}} \neq D_{j}\right) \\
& =\frac{\exp \left[\left(V_{D j}+V_{n e s t}\right) \mu^{h i g h}\right]}{\sum_{j^{\prime} \varepsilon J} \exp \left[\left(V_{D j^{\prime}}+V_{n e s t}\right) \mu^{h i g h}\right]} \\
& =\frac{\exp \left\{V_{D j}+\frac{1}{\mu^{l o w}} \ln \sum_{k \varepsilon K} \exp \left[\left(V_{T k}+V_{D j T k}\right) \mu^{l o w}\right] \mu^{h i g h}\right\}}{\sum_{j^{\prime} \varepsilon J} \exp \left[\left(V_{D j^{\prime}}+V_{\text {nest }}\right) \mu^{\text {high }}\right]} \\
& P\left(T_{k} \mid D_{j}\right)=\frac{\exp \left[\left(V_{T k}+V_{D j T k}\right) \mu^{l o w}\right]}{\sum_{k^{\prime} \varepsilon K} \exp \left[\left(V_{T k^{\prime}}+V_{D j T k^{\prime}}\right) \mu^{l o w}\right]}
\end{aligned}
$$

A nested logit model in which transportation is hierarchically structured over destination is derived analogously.

Probit model. Let all elements be defined as before. Let $f\left(\varepsilon_{D j T k}, \ldots, \varepsilon_{D J T K}\right)$ be the density function of the normal distribution. Let $\varepsilon_{D j}, \varepsilon_{T k}, \varepsilon_{D j T k}$ be the IID normally distributed error terms over the utility of respectively the components $D_{j}$ and $T_{k}$ and their 
interaction $D_{j} T_{k}$ and let $\varepsilon_{\{D j k\}\}}$ be the sum of these three error terms. Then, the utility and choice probability of alternative $D_{j} T_{k}$ are expressed as

$$
\begin{gathered}
U_{D j T k}=V_{D j}+V_{T k}+V_{D j T k}+\varepsilon_{D j}+\varepsilon_{T k}+\varepsilon_{D j T k} \\
=\int_{-\infty}^{\infty} \int_{-\infty}^{V_{D j T k}-V_{D i T\}}+\varepsilon_{D J T k\}}} \ldots \int_{-\infty}^{V_{D j T k}-V_{D J T K}+\varepsilon_{D J T k}} f\left(D_{j} T_{k}\right) \\
f\left(\varepsilon_{\{D T k\}}, \ldots, \varepsilon_{\{D J T K\}}\right) d \varepsilon_{\{D j T k\}}, \ldots, d \varepsilon_{\{D J T K\}}
\end{gathered}
$$

The full underlying variance-covariance matrix of the error terms in the probit model for the combined destination and transportation choice is the variance-covariance structure expressed in Formulas 2 and 4 . This structure was discussed in the section on the role of the stochastic component.

Component-based logit model. Let $V_{D j .1}, V_{T k .1}$, and $V_{D j T k .1}$ respectively be the structural utilities specific to destination $D_{j}$, to transportation mode $T_{k}$ and to their interaction in the combined choice of destination and transportation $D_{j} T_{k}$ Let $V_{T k .2}$ and $V_{D j T k .2}$ be the structural utilities for these same elements, but with different parameters for the conditional choice of destination, and let $V_{D j .3}$ and $V_{D j T k .3}$ be the structural utilities for the conditional choice of transportation. Let $\varepsilon_{D j T k .1}$ be the error term for these structural utilities in the combined choice, and $\varepsilon_{T k \mid D j .2}$ and $\varepsilon_{D j \mid T k .3}$ be IID Gumbel error terms for the structural utilities in the conditional destination and transportation choice, respectively. This structure implies that separate logit models are estimated for the choices for each combination of components in the portfolio. Formally, the utility functions are expressed as

$$
\begin{aligned}
& U_{D j T k}=V_{D j .1}+V_{T k .1}+V_{D j T k .1}+\varepsilon_{D j T k .1} \\
& U_{T k \mid D j}=V_{T k .2}+V_{D j T k .2}+\varepsilon_{T k ! D j .2} \\
& U_{D j \mid T k}=V_{D j .3}+V_{D j T k .3}+\varepsilon_{D j \mid T k .3}
\end{aligned}
$$

\section{Design Strategy}

The proposed model formulations involve more flexible specifications of the error term than typically used in conventional conjoint choice experiments. One of the basic assumptions of traditional experimental designs is that the stochastic parts of the utilities follow IID distributions. This is a necessary condition for fractional factorial experimental designs to support efficient estimation of parameter values (Dey, 1985). However, if error terms are interdependent and/or heteroscedastic, this assumption may give rise to biases in the model estimates: To understand the effect of these biases, it is critical to realize that the estimated parameter values for the structural utilities $V$ are confounded with the scale parameter $\mu$ in the simple multinomial logit model and that only the product of $\mu$ and $V$ can be estimated. In the estimation process the scale parameter $\mu$ is therefore generally set to 1 and the structural parameters are estimated in relation to this value (Ben-Akiva \& Lerman, 1985 p. 71). As a consequence, choice situations with identical structural parameter values but different underlying scale parameters do not lead to identical parameter estimates. Estimates from choice situations with different error terms lead to different parameter estimates because there is a direct relationship between the variance of the error term and the scale parameter $\mu$ in logit and probit models. 
As shown in the discussion of the nested logit and probit model of portfolio choices, covariances between the error terms of portfolios typically occur if separate components that make up portfolios each have separate error terms. As argued before, statistically efficient estimation of the separate influence of this effect is not possible with traditional designs. We therefore propose a design approach that supports explicit estimation for choice situations describing choices between various combinations of pörtfolio components. This approach offers the possibility to test whether a component-based logit model with different estimates for each choice situation can be reduced to less complex overall models such as the probit, nested logit, and joint logit models, and also whether different error terms are required for the different choice situations, that is, to test the probit-and nested logit model against the joint logit model. The reason that this testing is feasible is that independent estimates can be obtained for the structural parameters in each portfolio situation. These estimates can be compared across choice situations to test for structural differences as well as scale differences. The objective of the prơposed design approach is twofold: (a) to support statistically efficient estimation of parameters in portfolio choice processes, and (b) to support tests of the model structures of joint logit, nested logit, and probit, and component-based logit choice models of portfolio choice as possible structures to explain tourists' portfolio choice processes.

Specifically, the proposed design approach consists of a set of interrelated subdesigns. The basic principle is that it supports separate estimates for the different choice component combinations that may occur in portfolio choice situations. The subdesigns can be distinguished in (a) a first subdesign that describes portfolio choices in which portfolios in each choice set vary on all their components and (b) a set of other subdesigns that describe conditional portfolio choices in which all but one component of the portfolio are identical within each choice.

The overall design is constructed in the following two steps:

(a) A first subdesign is constructed in analogy with traditional designs for single choices, with the difference that attributes from several components instead of the attributes of only one component are used to construct portfolios and that, within the choice sets, no common components are allowed between portfolios. Thus, even if the separate components in a portfolio choice carry separate error terms, as is the case in the probit model, the assumption of IID error terms holds within this subdesign. Statistically efficient parameter estimates are therefore supported by the subdesign. If the joint logit model applies, this design offers sufficient information to estimate all structural parameters. In the case of nested logit and probit models, independent parameter estimates of the structural parameters also can be obtained, but there is no information on the structure of the variance-covariance matrix that describes the error structure in the portfolio choices. In case of the component-based logit model, this subdesign provides the required estimates for the combined portfolio choice.

(b) A set of conditional subdesigns is constructed in which only one of the separate components of the portfolios varies and the others are maintained as a constant condition within the choice set. These subdesigns are introduced to allow for tests of the assumptions in the joint, nested, and probit models of identical underlying parameter values in the different component combinations in portfolio choices and to allow for estimates of the different models in the component-based logit model. Intuitively, the subdesigns can be considered as simulations of possible phases in the portfolio choice process, where respondents already have selected 
expressed as $2\left[L^{*}\left(\beta_{1}\right)-L^{*}\left(\beta_{2}\right)\right]$, where $L^{*}\left(\beta_{1}\right)$ and $L^{*}\left(\beta_{2}\right)$ are the adjusted log-likelihoods of the models under comparison. This statistic is asymptotically chi-square distributed.

In the estimation and model comparison procedure, separate models are estimated for choices in each subdesign. This procedure gives the estimates for the component-based logit model by estimating separate simple MNL models for each subdesign. These estimates are feasible because IID error terms exist within each subdesign, as discussed. Therefore, even if the probit model is the true underlying model, parameters can be estimated consistently within each subdesign by applying models that are based on IID error terms. Estimates based on the simple MNL model can be translated into probit parameters by applying the following transformation (Ben-Akiva \& Lerman, 1985, p. 71):

$$
\beta_{\text {logit }}=\frac{\pi}{\sqrt{6}} \beta_{\text {probit }}
$$

where $v a r_{\text {probit }}\left(\varepsilon_{i}\right)=1$ and $v a r_{\text {logit }}\left(\varepsilon_{i}\right)=\pi^{2} / 6$.

Next, the variance-covariance structure of the overall probit model is estimated by maximizing the log-likelihood of the observed choices across all choice sets and subjects. Again, the parameters for each of the subdesigns are optimized; however, this time a set of extra parameters $\mu$ is optimized simultaneously to express the difference in scale between the different subdesigns. A procedure based on the Swait and Louviere (1993) approach can be used for this purpose. It finds the optimal scale ratio by calculating the overall log-likelihood for a sequence of scale ratios. In this procedure, the parameter values of the first subdesign are kept constant relative to the parameters of the other subdesigns, and the optimum scale factor is determined between the parameters of the other subdesigns and the first. Thus, the second subdesign is optimized along with the first subdesign, then the third subdesign is optimized along with the first subdesign, and so forth.

Because the parameters of the other subdesigns are based on conditional portfolio choices that vary independently of each other, a sequential estimation procedure can be used to determine the scale factors that maximize the overall log-likelihood. This procedure guarantees a global maximum in the log-likelihood ratio statistic but does not provide values for the variance of the scaling values (Swait \& Louviere, 1993). However, in comparing model structures this is not a major drawback, because the log-likelihood ratio test statistic compares the total fit of the models rather than the separate parameter estimates. It is important to note that for this estimation to be effective the true underlying model in each subdesign needs to have IID error terms.

Estimates for the covariances in the variance-covariance matrix of the probit model can be derived directly from the estimated scale ratios. The covariance between conditional portfolio choices that have common components is equal to the variance of the error terms of those common elements. The estimated scale corrections between Subdesign 1 and the other subdesigns therefore equal the ratio of the variance of the overall error term in Subdesign 1 to the error terms in the each of the other subdesigns. If the scale of the parameters in Subdesign 1 is arbitrarily set to 1 (and consequently the variance to $\pi^{2} / 6$ ), the variance of the error term in subdesign $i$ can be expressed in terms of the ratio of the scales of the two subdesigns. First, the ratio of the scales of the subdesigns $\left(r_{1-i}\right)$ is expressed in terms of the standard deviations of the error terms of the subdesigns ( $\sigma_{1}$ and $\left.\sigma_{i}\right)$ 


$$
r_{1-i}=\frac{\mu^{1}}{\mu^{1}}=\frac{\sigma_{i}}{\sigma_{1}}=\frac{\sigma_{i}}{\pi / \sqrt{6}}
$$

Then the variance in subdesign $i$ can be expressed as

$$
\operatorname{var}\left(\varepsilon_{1}\right)=\frac{\pi^{2}}{6} r_{1-i}^{2}
$$

Because it is assumed that the error terms related to each of the separate components in the portfolio alternatives are independently distributed, the variance of the error term in Subdesign 1 minus the variance of the error term in subdesign $i$ equals $\operatorname{var}\left(\varepsilon_{1-i}\right)$ : the variance over the common components in the portfolio choices in subdesign $i$. In formula this is expressed as

$$
\operatorname{var}\left(\varepsilon_{1}\right)-\operatorname{var}\left(\varepsilon_{i}\right)=\operatorname{var}\left(\varepsilon_{1-i}\right)
$$

As was shown in the previous section, this variance equals the covariance for the conditional choices in subdesign $i$ if they are modeled in a probit variance-covariance structure. Therefore, the covariance related to choices between alternatives $i$ and $i^{\prime}$ in subdesign $i$ can be expressed as

$$
\begin{gathered}
\operatorname{cov}\left(\varepsilon_{i}+\varepsilon_{1-i}, \varepsilon_{i^{\prime}}+\varepsilon_{1-i}\right) \\
=\operatorname{cov}\left(\varepsilon_{1-i}, \varepsilon_{1-i}\right) \\
=\operatorname{var}\left(\varepsilon_{1-i}\right)
\end{gathered}
$$

where $\varepsilon_{i}$ and $\varepsilon_{i}$ are the sum of the error terms over the alternatives that vary in the portfolio choices in subdesign $i$ and $\varepsilon_{1-i}$ is the sum of the error terms over the alternatives that all portfolio alternatives in subdesign $i$ have in common.

Thus, the various model structures can be tested against each other in a series of log-likelihood ratio tests:

1. The separate models are tested against the overall probit model,

$$
\left.2\left[L^{*}(\text { component-based logit })-L^{*} \text { (overall probit }\right)\right]
$$

2. If the sum of the log-likelihoods of the component-based logit model across the subdesigns is not significantly better than that of the overall probit model, the overall probit model is tested against the different hierarchical structures of the overall nested logit model,

$$
\left.\left.2\left[L^{*} \text { (overall probit }\right)-L^{*} \text { (overall nested logit }\right)\right]
$$

3. If again there is no significant difference, the best fitting overall nested logit model is tested against the overall joint logit model:

$$
\left.\left.2\left[L^{*} \text { (overall nested logit }\right)-L^{*} \text { (overall joint logit }\right)\right]
$$

This series of tests allows one to evaluate the four model structures against each other. It makes use of the fact that the four structures are nested within each other in terms of their 
model complexity and the fact that the probit parameters can be transformed mathematically into logit parameters for the proposed model structure.

\section{Illustration}

The modeling and design strategy discussed above is illustrated in an empirical application to Dutch tourists' choices of short city trips in Belgium, Germany, or the Netherlands. These three countries are the most popular destinations for Dutch tourists' short breaks. Although Paris and London are the two major city destinations for Dutch tourists, the cities in Belgium and Germany are generally regarded as more direct competitors to Dutch cities because they are similar to Dutch urban destinations in terms of the travel time required, costs involved, and number of tourist attractions.

\section{Method}

Choice data for this study were collected in June and July 1993 in the Eindhoven region of the Netherlands. Questionnaires were mailed to 2,040 randomly selected households and later personally collected at the door. This sample was combined with a sample of 480 respondents who were contacted through travel organizations and received questionnaires along with their tickets. Response rates were $31 \%$ and $11 \%$, respectively. Of the respondents, only those who had made a city trip in the past 3 years were selected. These respondents represented $97 \%$ of the total response.

Identification of the attributes that influence individuals' vacation behavior was based on a literature survey (Jansen-Verbeke, 1988; Woodside et al., 1989). These attributes were then discussed with a group of experts in Dutch tourism marketing; this discussion led to a final list of attributes to be included in the experiment. Cities in the experiment were located in three different countries (the Netherlands, Belgium, and Germany) and at three different distances $(75 \mathrm{~km}, 100 \mathrm{~km}$, and $125 \mathrm{~km}$ ). Three types of urban tourist facilities were included (restaurants and bars, shopping facilities, and special sights), each of which was presented at three different levels of availability (few, many, and very many). Hotel facilities were described in terms of price (NLG 50, NLG 75, or NLG 100), quality (two-star, three-star, or four-star accommodation) and location (city center, near city center, or at city border). Transportation was described in terms of transportation mode (bus, train, or car), price (NLG 30, NLG 45, or NLG 60 for bus; NLG 45, NLG 60, or NLG 75 for train) and travel time $(1.5 \mathrm{hr}, 2 \mathrm{hr}$, or $2.5 \mathrm{hr})$. Interactions between the country of destination and the availability of special sights and between travel distance to the destination and required travel time were included. The list of attributes and their levels is given in Table 2. Car was presented as a base alternative in the choice task and is therefore not included in this table.

The experimental design was constructed according to the design strategy explained in the previous section:

1. First, a subdesign was constructed to support estimation of main effects and interaction effects for choices between portfolios that differed on their destination and transportation components. For each transportation mode (bus and train), a $3^{10}$ design (fractionalized into 81 profiles) was used to generate the alternatives ( $3^{2}$ for transportation attributes and $3^{\circ}$ for destination attributes). Profiles from the designs 
Table 2

Attributes in combined destination and transportation choice experiment

\begin{tabular}{llll}
\hline \multicolumn{1}{c}{ Variable } & Choice 1 & Choice 2 & Choice 3 \\
\hline Destination & Netherlands & Germany & Belgium \\
Area & $75 \mathrm{~km}$ & $100 \mathrm{~km}$ & $125 \mathrm{~km}$ \\
Distance & few & many & very many \\
Restaurants and bars & few & many & very many \\
Shopping facilities & few & many & very many \\
Special sights & NLG 50 & NLG 75 & NLG 100 \\
Hotel price & 2 -star & 3 -star & 4 -star \\
Hotel quality & city center & near center & city border \\
Hotel location & - & - & - \\
Interaction area and sights & & & \\
Transportation & NLG 30 & NLG 45 & NLG 60 \\
Price (bus) & NLG 45 & NLG 60 & NLG 75 \\
Price (train) & $1.5 \mathrm{hr}$ & $2 \mathrm{hr}$ & $2.5 \mathrm{hr}$ \\
Travel time (bus) & $1.5 \mathrm{hr}$ & $2 \mathrm{hr}$ & $2.5 \mathrm{hr}$ \\
Travel time (train) & - & - & - \\
Interaction distance and time (bus) & - & - & - \\
Interaction distance and time (train) & - & & \\
\hline
\end{tabular}

for each mode were randomly combined to create choice sets of two alternatives, restricting the possible combinations to those that did not share the same destinations. This procedure guarantees orthogonality within, but not between, choice alternatives.

2. A second subdesign was constructed for portfolio choices of destination components conditional on transportation. It consisted of two parts: a first part in which destinations varied given a certain bus as transportation mode, and a second part in which destinations varied given a certain train as transportation mode. For these parts two $3^{2} \times 3^{8}$ designs (fractionalized into 32 profiles) were used. To create choice sets, profiles with identical transportation mode descriptions were randomly combined into sets of two. This procedure guarantees orthogonality within main effects of each alternative, but not between alternatives, and no interactions can be estimated.

3. A third subdesign was constructed for portfolio choices of transportation components, conditional on destination. In this design transportation components varied for a given destination in a $3^{8} \times 3^{2} \times 3^{2}$ design presented in 64 profiles. Destinations varied across the different choice sets but were constant within each set. This design guarantees orthogonality both within and between main effects of the alternatives. Main effects can be estimated independently from second order interactions, but the interaction effects themselves are confounded.

Thus, the total design consisted of $209(81+2 * 32+64)$ different portfolio choice sets. A base portfolio ailternative was added to each choice set. It described a city trip by car to an unattractive combination of destination attributes. For the conditional choices in the design (e.g., choosing a destination for a given mode of transportation), the base was changed to the given condition (i.e. the given mode of transportation or destination).

Schematically, the experimental design can be summarized as follows: 


\begin{tabular}{|c|c|c|c|c|c|c|}
\hline & Dest $_{1}$ & $B u s_{1}$ & Dest $_{2}$ & $\operatorname{Train}_{2}$ & Dest $_{\text {base }}$ & Car $_{\text {base }}$ \\
\hline Subdesign 1 & $3^{8}$ & $3^{2}$ & $3^{8}$ & $3^{2}$ & 1 & 1 \\
\hline Subdesign $2 a$ & $3^{8}$ & $3^{2}$ & $3^{8}$ & 0 & 1 & 0 \\
\hline Subdesign $2 b$ & $3^{8}$ & 0 & $3^{8}$ & $3^{2}$ & 1 & 0 \\
\hline Subdesign 3 & $3^{8}$ & $3^{2}$ & 0 & $3^{2}$ & 0 & \\
\hline
\end{tabular}

Respondents in the experimental task were asked to imagine that they were planning a weekend city break in the near future. In each choice set they were asked to allocate 100 points over the trip options to reflect their preferences. The 100 points for each choice set were rescaled to 1 point in the estimation to reflect the fact that they represented one single observation rather than 100 different observations. An example of a choice set given to respondents is presented in Figure 1. Each respondent was offered 12 such choice sets, which were randomly drawn from the different subdesigns so that the expected number of responses per choice set was identical for all choice sets. Responses were aggregated across respondents in the analysis.

\section{Analyses and Results}

\section{Component-Based Logit Model}

The component-based logit model was estimated, which consisted of separate logit models for Subdesigns 1 and 3 and a separate logit model combining the observations for Subdesigns $2 a$ and $2 b$, which were both destination choices conditional on transportation mode. These three models together represented the component-based logit model of three separate logit models for the combined portfolio choices and the two possible conditional portfolio choices.

The results of the separate model estimations for the three portfolio component combinations are presented in Tables 3, 4, 5, and 6. The parameters represent estimates based on the first- and second-order orthogonal polynomial coding for the three level attributes. In this coding scheme, Level 1 is coded as $(-1,1)$, Level 2 as $(0,-2)$, and Level 3 as $(1,1)$. Thus, the first parameter represents the contrast between the first and the third level, and the second parameter represents a contrast between the second and the other two levels.

Tables 3 and 4 contain estimates for the combined transportation and destination choices. Parameter values generally had the expected signs; that is, utility increased with more shopping facilities and decreased with less facilities and was a monotonic decreasing function of price. The most important attributes were special city sights and shopping facilities. Although significant, hotel characteristics generally were somewhat less important, as was the presence of restaurants and bars. Insignificant in this choice process were geographical area, travel distance, travel time, travel costs, and all observable interactions. The difference between bus and train was also not significant.

Some insignificant parameters in the models for overall choices in the first subdesign had unexpected values, which disappeared in the conditional choice models, where they also were more significant. This result may be because of the fact that respondents in the combined choice condition did not evaluate the less important attributes systematically. However, such attributes were evaluated more consistently when attention was more focused, as was the case in the conditional choices. 
Please divide 100 points over the following three city breaks to indicate your preference for each trip

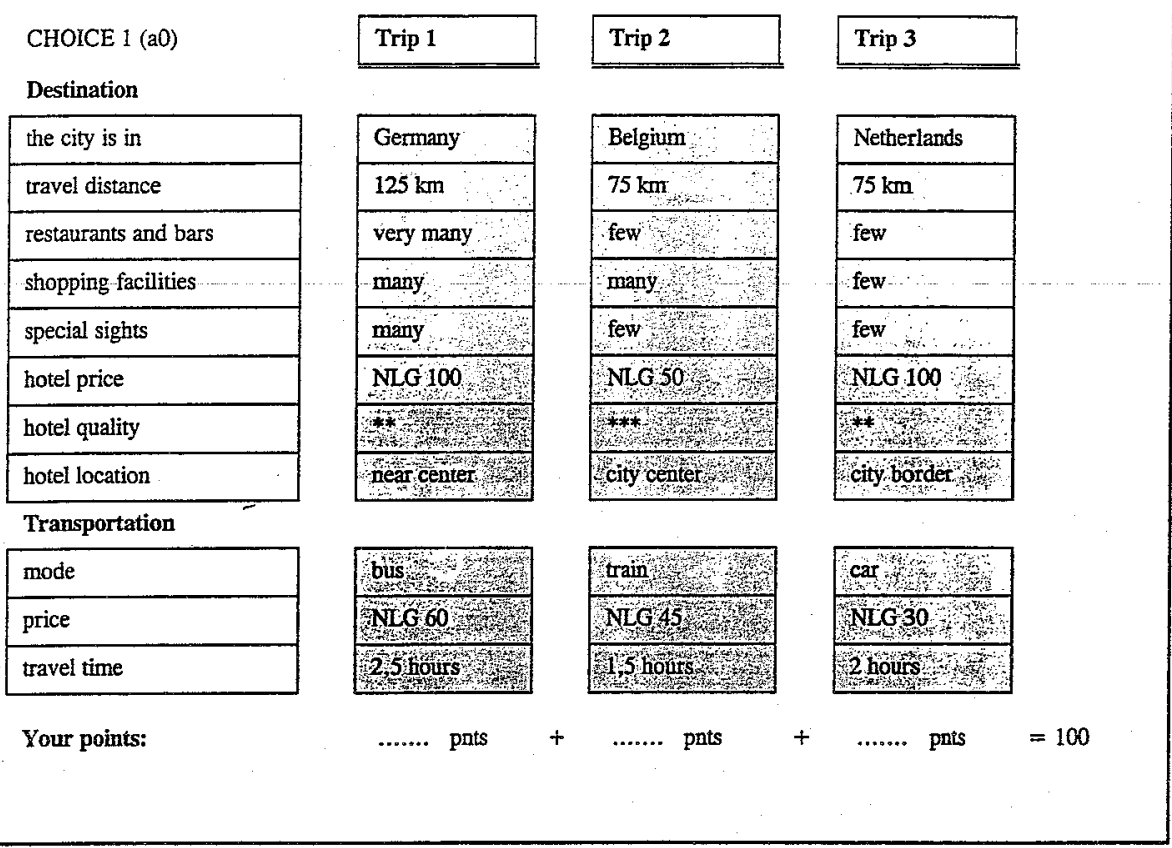

Figure 1. Example of a combined destination and transportation choice task presented to respondents.

Tables 5 and 6 contain the results for the conditional portfolio choices of destination and transportation. The estimated model parameters in Table 5 represent the results for the choice of destination given transportation mode. The signs of the parameters were as expected and consistent with estimates for the combined portfolio choices. Table 6 shows that in conditional choice sets for transportation, bus and train attributes were considerably more significant than in choice sets for combined portfolio choices and also had the expected signs. The difference between bus and train alternatives, again was not significant. In general, parameters in conditional portfolio choices were more significant than those in combined portfolio choices.

\section{Probit Model}

To test whether a probit model structure was statistically superior to the three separate models in the component-based logit model, parameters estimated from conditional choices were constrained to be equal up to a scale correction to the parameters estimated from the combined choices. In this test, the scale of the combined portfolio choices was arbitrarily set to 1 . Alternative specific constants were not rescaled, because their values depended purely on the average utility level of the alternatives in the respective subdesigns. The estimated scale ratio between the conditional destination choices and the combined choices was 0.8502 . This finding implies that parameter estimates for combinations of transportation and destination choice on average were 0.8502 times those estimated from conditional destination choices. Hence, smaller errors were associated with choices of destination than with choices of both transportation and destination. The 
scale ratio between the conditional transportation choices and the combined choices was estimated as well. It was 0.3194 , suggesting that smaller errors were associated with conditional transportation choices than with combined destination transportation choices. Both findings support the conclusion that choices for different combinations of components of portfolios differ only in terms of their error structure and not in terms of their structural component. Specifically, this finding supports the probit model"over the component-based logit model.

The results of the overall estimation are in Table 7. Insignificant interaction effects were omitted from this table, because they were not included as part of the rescaling tests. The corresponding utilities are in Tables 8 and 9 . They are calculated by multiplying the orthogonal coding values with the parameters in Tables 3 through 7. Probit parameters can be calculated from the reported parameters by applying the logit transformation that was discussed in the estimation section (see Formula 16). Covariances can be calculated from the reported ratio of scales, as was discussed also in the estimation section (see Formula 20).

\section{Nested Logit and Joint Logit}

The nested logit model and joint logit model also have identical structural parameters across subdesigns. The models differ from each other in terms of the expected scale

\section{Table 3}

Estimates for Subdesign 1: Combined portfolio choice of destination and transportation, destination parameters

\begin{tabular}{lrrr}
\hline \multicolumn{1}{c}{ Attribute } & $\begin{array}{c}\text { Parameter } \\
\text { estimate }\end{array}$ & $\begin{array}{c}\text { Standard } \\
\text { error }\end{array}$ & $t$ value \\
\hline Intercept & $\mathbf{0 . 7 8 0 4 4}$ & 0.05740 & 13.597 \\
Area & -0.00626 & 0.04414 & -0.142 \\
& -0.04135 & 0.02438 & -1.696 \\
Distance & -0.01634 & 0.04263 & -0.383 \\
Restaurants and bars & -0.01373 & 0.02458 & -0.559 \\
Shopping facilities & $\mathbf{0 . 0 9 0 8 4}$ & 0.04199 & 2.163 \\
& 0.01655 & 0.02636 & 0.628 \\
Special sights & $\mathbf{0 . 1 6 1 8 8}$ & 0.04456 & 3.561 \\
& $\mathbf{0 . 0 4 1 7 2}$ & 0.02524 & 1.623 \\
Hotel price & $\mathbf{0 . 2 3 9 0 0}$ & 0.04219 & 5.579 \\
& $\mathbf{0 . 0 4 8 9 1}$ & 0.02233 & 2.146 \\
Hotel quality & $\mathbf{0 . 0 8 4 2 0}$ & 0.04214 & -1.964 \\
& -0.00511 & 0.02372 & -0.211 \\
Hotel location & $\mathbf{0 . 1 0 5 3 1}$ & 0.04747 & 2.172 \\
& 0.00224 & 0.02429 & 0.090 \\
Interaction: Area and sights & $\mathbf{0 . 0 8 8 4 5}$ & 0.03940 & 2.200 \\
$A_{1} \cdot S_{1}$ & 0.00801 & 0.02397 & 0.396 \\
$A_{1} \cdot S_{2}$ & & & \\
$A_{2} \cdot S_{1}$ & 0.00812 & 0.05451 & 0.149 \\
$A_{2} \cdot S_{2}$ & -0.00840 & 0.02982 & -0.282 \\
\hline & 0.02285 & 0.03124 & 0.732 \\
\hline
\end{tabular}

Note. McFadden's $p^{2}=0.35134$. Boldface indicates significance at $95 \%$ confidence level. 
Table 4

Estimates for Subdesign 1: Combined portfolio choice of destination and transportation, transportation parameters

\begin{tabular}{lrrr}
\hline \multicolumn{1}{c}{ Attribute } & $\begin{array}{c}\text { Parameter } \\
\text { estimate }\end{array}$ & $\begin{array}{c}\text { Standard } \\
\text { error }\end{array}$ & $t$ value \\
\hline General difference between bus and train & -0.02222 & 0.02513 & -0.884 \\
Price (bus) & -0.01442 & 0.06075 & -0.237 \\
& -0.00661 & 0.03440 & -0.192 \\
Travel time (bus) & -0.05906 & 0.06006 & -0.983 \\
& -0.01938 & 0.03484 & -0.556 \\
Price (train) & -0.04117 & 0.05804 & -0.709 \\
& 0.01823 & 0.03429 & 0.534 \\
Travel time (train) & -0.00936 & 0.05959 & -0.157 \\
& -0.01275 & 0.03412 & -0.372 \\
Interaction: Distance and travel time (bus) & & & \\
$D_{1} \cdot T b_{1}$ & 0.06792 & 0.07347 & 0.924 \\
$D_{1} \cdot T b_{2}$ & 0.00545 & 0.04301 & 0.127 \\
$D_{2} \cdot T b_{1}$ & 0.00464 & 0.04310 & 0.108 \\
$D_{2} \cdot T b_{2}$ & 0.00040 & 0.02503 & 0.016 \\
Interaction: Distance and travel time (train) & & & \\
$D_{1} \cdot T t_{1 .}$ & 0.03205 & 0.07069 & 0.453 \\
$D_{1} \cdot T t_{2}$ & -0.00504 & 0.04256 & -0.118 \\
$D_{2} \cdot T t_{1}$ & -0.03989 & 0.04264 & -0.936 \\
$D_{2} \cdot T t_{2}$ & 0.01230 & 0.02519 & 0.488 \\
\hline
\end{tabular}

Note. McFadden's $p^{2}=0.35134$.

differences between the combined and conditional portfolio choices. In the nested logit model, it is expected that one of the conditional choice situations is scaled identically to the combined choices, and the other is expected to have a larger scale (i.e. smaller variance). This structure indicates the hierarchical structure of the nested logit model. In the joint logit model, all combined and conditional choices are expected to be scaled identically.

\section{Testing the Models}

To test the explanatory power of the different models against each other the following likelihood ratio test's were performed:

1. The component-based logit structure was tested against the probit model.

2. The probit model was tested against the two possible nested logit model specifications (i.e., based on either destination or transportation being nested under the other) in which one covariance is set equal to zero.

3. The best fitting nested logit model was tested against the joint logit structure in which both covariances were set equal to zero.

If the log-likelihood of the probit model is not significantly lower than that of the component based logit model, the hypothesis of identical structural parameter values cannot be rejected. If the log-likelihood of the probit model compared with two possible nested logit models with corrections on only one conditional choice is not significantly higher, at least one scale ratio correction is not required to model underlying choice structure. If the joint logit model is more appropriate than the nested logit model, the scale corrections 
Table 5

Estimates for Subdesign 2: Conditional destination choice

\begin{tabular}{lrcr}
\hline \multicolumn{1}{c}{ Attribute } & $\begin{array}{c}\text { Parameter } \\
\text { estimate }\end{array}$ & $\begin{array}{c}\text { Standard } \\
\text { error }\end{array}$ & $t$ value \\
\hline Intercept choices conditional on train & $\mathbf{0 . 7 8 3 1 6}$ & 0.10618 & 7.376 \\
Intercept choices conditional on bus & $\mathbf{0 . 9 1 7 7 2}$ & 0.10724 & 8.558 \\
Area & 0.01010 & 0.05503 & 0.183 \\
& -0.02295 & 0.03055 & -0.751 \\
Distance & 0.00117 & 0.04326 & 0.027 \\
& 0.02278 & 0.02655 & 0.858 \\
Restaurants and bars & $\mathbf{0 . 1 0 2 0 5}$ & 0.04374 & 2.333 \\
& -0.00928 & 0.03259 & -0.285 \\
Shopping facilities & $\mathbf{0 . 1 4 7 5 3}$ & -0.04272 & 3.454 \\
& 0.00626 & 0.03182 & 0.197 \\
Special sights & $\mathbf{0 . 3 0 1 0 0}$ & 0.04403 & 6.836 \\
Hotel price & 0.03550 & 0.02763 & 1.285 \\
& $-\mathbf{0 . 1 4 5 6 6}$ & 0.04532 & -3.214 \\
Hotel quality & 0.00248 & 0.03234 & 0.077 \\
& $\mathbf{0 . 1 0 7 6 5}$ & 0.04338 & 2.482 \\
Hotel location & 0.00128 & 0.03139 & 0.041 \\
& 0.07632 & 0.04327 & 1.764 \\
\end{tabular}

Note. McFadden's $\rho^{2}=0.47766$. Boldface indicates significance at $95 \%$ confidence level.

between combined choices and conditional choices should not significantly improve model fit.

The results were as follows:

1. The log-likelihood of the component-based logit model (based on three separate models) was -754.63 , and that of the overall probit model was -757.28 . The $\log$-likelihood ratio test statistic had a value of 5.30, which is not significant at the

Table 6

Estimates for Subdesign 3: Conditional transportation choice

\begin{tabular}{lccr}
\hline \multicolumn{1}{c}{ Attribute } & $\begin{array}{c}\text { Parameter } \\
\text { estimate }\end{array}$ & $\begin{array}{c}\text { Standard } \\
\text { error }\end{array}$ & \multicolumn{1}{c}{$t$ value } \\
\hline Intercept & $-\mathbf{0 . 8 5 7 0 6}$ & 0.05438 & -15.762 \\
General difference between bus and train & -0.02563 & 0.04247 & -0.604 \\
Price (bus) & $-\mathbf{0 . 1 4 9 7 4}$ & 0.07352 & -2.036 \\
& -0.00988 & 0.04783 & -0.207 \\
Travel time (bus) & -0.10775 & 0.07263 & -1.484 \\
& -0.03306 & 0.04499 & -0.735 \\
Price (train) & -0.12693 & 0.07006 & -1.812 \\
& 0.03929 & 0.04654 & 0.844 \\
Travel time (train) & -0.10948 & 0.07166 & -1.528 \\
& 0.01296 & 0.04514 & 0.287
\end{tabular}

Note. McFadden's $p^{2}=0.37475$. Boldface indicates significance at $95 \%$ confidence level. 
0.05 level in a chi-square test at 25 degrees of freedom (i.e. the number of extra parameters in the separate models). Thus the separate models did not describe the observations significantly better than the overall probit model.

2. Log-likelihood results for the nested logit models were calculated as follows: (a) destination choices were rescaled relative to combined choices, and (b) transportation choices were rescaled relative to combined choices. The log-likelihoods were, respectively, -759.29 and -757.83 . The log-likelihood ratio test statistics against the overall probit model were, respectively, 4.02 for the first model and 1.10 for the second. Only the first model fitted significantly worse than the probit model in the log-likelihood ratio test at 1 degree of freedom for one omitted scale.

\section{Table 7}

Overall estimates

\begin{tabular}{|c|c|c|c|c|}
\hline . & Attribute & $\begin{array}{l}\text { Parameter } \\
\text { estimate }\end{array}$ & $\begin{array}{c}\text { Standard } \\
\text { error }\end{array}$ & $t$ value \\
\hline \multicolumn{2}{|c|}{ Intercept subdesign 1} & 0.78044 & 0.05740 & 13.597 \\
\hline \multicolumn{2}{|c|}{ Intercept subdesign 2 (conditional on train) } & 0.67651 & 0.08776 & 7.708 \\
\hline \multicolumn{2}{|c|}{ Intercept subdesign 2 (conditional on bus) } & 0.79182 & 0.08891 & 8.906 \\
\hline \multicolumn{2}{|c|}{ Intercept subdesign 3} & -0.27308 & 0.01716 & -15.913 \\
\hline \multirow{2}{*}{\multicolumn{2}{|c|}{ Area }} & -0.00703 & 0.03077 & -0.229 \\
\hline & & -0.03174 & 0.01714 & -1.852 \\
\hline \multirow{2}{*}{\multicolumn{2}{|c|}{ Distance }} & -0.01256 & 0.02746 & -0.458 \\
\hline & & 0.00450 & 0.01637 & 0.275 \\
\hline \multirow{2}{*}{\multicolumn{2}{|c|}{ Restaurants and bars }} & 0.09064 & 0.02734 & 3.315 \\
\hline & & 0.00739 & 0.01848 & 0.400 \\
\hline \multirow{2}{*}{\multicolumn{2}{|c|}{ Shopping facilities }} & 0.14452 & 0.02735 & 5.285 \\
\hline & & 0.02587 & 0.01825 & 1.417 \\
\hline \multirow{2}{*}{\multicolumn{2}{|c|}{ Special sights }} & 0.25492 & 0.02778 & 9.177 \\
\hline & & 0.04038 & 0.01595 & 2.532 \\
\hline \multirow{2}{*}{\multicolumn{2}{|c|}{ Hotel price }} & -0.10452 & 0.02812 & -3.717 \\
\hline & & 0.00178 & 0.01769 & 0.010 \\
\hline \multirow[t]{2}{*}{ Hotel quality } & & 0.09886 & 0.02848 & 3.471 \\
\hline & & 0.00377 & 0.01770 & 0.213 \\
\hline \multirow[t]{2}{*}{ Hotel location } & & 0.07211 & 0.02666 & 2.705 \\
\hline & $\cdots \vartheta^{4 \prime \prime}$ & 0.01162 & 0.01764 & 0.659 \\
\hline \multicolumn{2}{|c|}{ General difference between bus and train } & -0.02222 & 0.02513 & -0.884 \\
\hline \multicolumn{2}{|l|}{ Price (bus) } & -0.04537 & 0.02170 & -2.090 \\
\hline \multirow{3}{*}{\multicolumn{2}{|c|}{ Travel time (bus) }} & -0.00287 & 0.01392 & -0.206 \\
\hline & & -0.03859 & 0.02151 & -1.794 \\
\hline & & -0.01144 & 0.01323 & -0.865 \\
\hline \multirow{2}{*}{\multicolumn{2}{|c|}{ Price (train) }} & -0.03931 & 0.02067 & -1.902 \\
\hline & & 0.01300 & 0.01355 & 0.959 \\
\hline \multirow{2}{*}{\multicolumn{2}{|c|}{ Travel time (train) }} & -0.03194 & 0.02113 & -1.511 \\
\hline & & 0.00202 & 0.01317 & 0.153 \\
\hline
\end{tabular}

Note. Scale factors: Subdesign 2 versus Subdesign 1, 0.8502; Subdesign 3 versus Subdesign 1 , 0.3194 .

McFadden's $\rho^{2}=0.3998$. Boldface indicates significance at $95 \%$ confidence level. 
Table 8

Utility values of attribute levels, destination attributes

\begin{tabular}{|c|c|c|c|c|}
\hline Attribute & $\begin{array}{l}\text { Destination- } \\
\text { transportation } \\
\text { choice }\end{array}$ & $\begin{array}{c}\text { Conditional } \\
\text { destination } \\
\text { choice }\end{array}$ & $\begin{array}{c}\text { Conditional } \\
\text { transportation } \\
\text { choice }\end{array}$ & Overall \\
\hline \multicolumn{5}{|l|}{ Area } \\
\hline Belgium & 0.03510 & 0.03305 & - & 0.02471 \\
\hline Germany & -0.08270 & -0.04590 & - & -0.06348 \\
\hline Netherlands & 0.04761 & 0.01286 & - & 0.03877 \\
\hline \multicolumn{5}{|l|}{ Distance } \\
\hline $125 \mathrm{~km}$ & -0.00260 & -0.02160 & - & -0.01706 \\
\hline $100 \mathrm{~km}$ & -0.02746 & 0.04556 & - & 0.00900 \\
\hline $75 \mathrm{~km}$ & 0.03007 & -0.02395 & $\therefore \quad=$ & 0.00806 \\
\hline \multicolumn{5}{|c|}{ Restaurants and bars } \\
\hline very many & 0.07430 & 0.11133 & - & 0.08325 \\
\hline many & 0.03309 & -0.01856 & - & 0.01478 \\
\hline few & -0.10739 & -0.09276 & - & -0.09802 \\
\hline \multicolumn{5}{|l|}{ Shopping facilities } \\
\hline very many & 0.12016 & 0.14127 & - & 0.11866 \\
\hline many & 0.08345 & 0.01251 & - & 0.05173 \\
\hline few & -0.20360 & -0.15378 & - & -0.17039 \\
\hline \multicolumn{5}{|l|}{ Special sights } \\
\hline very many & 0.19010 & 0.26550 & - & 0.21454 \\
\hline many & 0.09781 & 0.07099 & - & 0.08076 \\
\hline few & -0.28790 & -0.33649 & - & -0.29529 \\
\hline \multicolumn{5}{|l|}{ Hotel price } \\
\hline NLG 50 & 0.07909 & 0.14317 & - & 0.10470 \\
\hline NLG 75 & 0.01023 & 0.00497 & - & -0.00035 \\
\hline NLG 100 & -0.08931 & -0.14813 & - & -0.10434 \\
\hline \multicolumn{5}{|l|}{ Hotel quality } \\
\hline 4-star & 0.10308 & 0.10636 & - & 0.09509 \\
\hline 3-star & 0.00447 & 0.00257 & - & 0.00754 \\
\hline 2-star & -0.10755 & -0.10893 & - & -0.10262 \\
\hline \multicolumn{5}{|l|}{ Hotel location } \\
\hline city center & 0.08045 & 0.06514 & - & 0.06049 \\
\hline near city center & 0.01601 & 0.02237 & - & 0.02324 \\
\hline at city border & -0.09645 & -0.08750 & - & -0.08373 \\
\hline
\end{tabular}

parameter. The second model did not fit significantly worse. Thus a model with transportation choice nested under destination choice was appropriate for this application, and a rescaling for conditional transportation choices was required.

3. Consequently, the overall joint logit model was rejected in favor of the nested logit model because one of the scale corrections produced a significant improvement in model fit.

\section{Conclusions and Discussion}

This study presented a methodology for investigating four model structures for urban tourists' portfolio choices of destination and transportation components: a joint logit 
Table 9

Utility values of attribute levels, transportation attributes

\begin{tabular}{|c|c|c|c|c|}
\hline Attribute & $\begin{array}{l}\text { Destination- } \\
\text { transportation } \\
\text { choice }\end{array}$ & $\begin{array}{l}\text { Conditional } \\
\text { destination } \\
\text { choice }\end{array}$ & $\begin{array}{l}\text { Conditional } \\
\text { transportation } \\
\text { choice }\end{array}$ & Overall \\
\hline General bus & -0.02222 & - & -0.02563 & -0.02222 \\
\hline General train & 0.02222 & - & 0.02563 & 0.02222 \\
\hline \multicolumn{5}{|l|}{ Price (bus) } \\
\hline NLG 30 & 0.00781 & - & 0.13983 & 0.04250 \\
\hline NLG 45 & 0.01323 & - & 0.01976 & 0.00573 \\
\hline NLG 60 & -0.02103 & - & -0.15958 & -0.04823 \\
\hline \multicolumn{5}{|c|}{ Travel time (bus) } \\
\hline $1.5 \mathrm{hr}$ & 0.03968 & - & 0.07470 & 0.02715 \\
\hline $2 \mathrm{hr}$ & 0.03876 & - & 0.06612 & 0.02287 \\
\hline $2.5 \mathrm{hr}$ & -0.07843 & - & -0.14081 & -0.05002 \\
\hline \multicolumn{5}{|l|}{ Price (train) } \\
\hline NLG 45 & 0.05950 & 一 & 0.16622 & 0.05231 \\
\hline NLG 60 & -0.03665 & - & -0.07857 & -0.02600 \\
\hline NLG 75 & -0.02284 & 一 & -0.08764 & -0.02630 \\
\hline \multicolumn{5}{|l|}{ Travel time } \\
\hline $1.5 \mathrm{hr}$ & -0.00338 & - & 0.12244 & 0.03396 \\
\hline $2 \mathrm{hr}$ & 0.02550 & - & -0.02592 & -0.00403 \\
\hline $2.5 \mathrm{hr}$ & -0.02211 & - & -0.09651 & -0.02992 \\
\hline
\end{tabular}

model, two nested logit models, a probit model, and a component-based logit model. The models were tested in a conjoint choice application of Dutch tourists' choices of short city breaks to destinations in Belgium, Germany, and the Netherlands. The application provides support for the theoretical assumption that destination and transportation choices are differently scaled, but that the underlying attribute values in combined and conditional portfolio choices are not significantly different after rescaling. It was shown that the suggested experimental approach adequately supports the parameters estimations for the proposed models for two component portfolio choices. It also was shown that the approach allows for tests of the relatively complex component based logit model. This approach allowed the investigation of separate models for choices of different portfolio component combinations against more parsimonious overall models such as the probit model, the nested logit model, and the joint logit model.

As expected, covariances did exist between the error terms for portfolios with common components. Of these, the covariance between portfolios that shared the same transportation component did not significantly improve the model fit, but the covariance between portfolios that shared the destination component did. This finding suggests that in this application the nested logit model with transportation nested under destination was most appropriate. Therefore, models estimated for urban tourists' separate transportation choices should not be used to predict transportation choices in combined destination transportation portiolio choices unless appropriate scale corrections are made.

Contrary to our expectations, interactions between the separate alternatives that made up the portfolio alternatives were not significant in the case study. If this result can be generalized to other choice situations, it potentially can reduce the required number of 
profiles in experimental designs for transportation-destination portfolio choices, because interactions in experimental approaches generally increase the size of the applied design.

The main managerial implication of our research findings is that strategic urban planning and marketing decisions regarding urban tourists' destination, and especially transportation, choices should not be based on separate studies of destination and transportation choices. In a more general sense, planning strategies based on separate models of tourists' service purchases may seriously overestimate the influence that planning and marketing strategies have on urban tourists' use of these services if the services are in fact purchased in a portfolio combination with other services rather than separately. To be most effective, planning and marketing strategies that aim to influence tourists' portfolio choices ideally should address the most important components in their portfolio choices and should be adjusted to the specific choice stage in which the tourists' choices are made. This stage can be discovered only if tourists' portfolio choices are studied, rather than their choices of separate components in the portfolio. For the specific choice process that was studied, our findings suggest that urban tourists' transportation-destination portfolio choices can be targeted most effectively through campaigns that address the destination components of their choices.

\section{References}

Ahn, K. H., \& Ghosh, A. (1989). Hierarchical models of store choice. International Journal of Retailing, 4, 39-52.

Arentze, T. A., Borgers, A. W. J., \& Timmermans, H. J. P. (1993). A model of multi-purpose shopping trip behaviour. Papers in Regional Science, 72, 239-256.

Ben-Akiva, M., \& Lerman, S. (1985). Discrete choice analysis. Cambridge, MA: MIT Press.

Bunch, D. S., \& Kitamura, R. (1989). Multinomial probit model estimation revisited: Testing of new algorithms and evaluation of alternative model specifications for trinomial models of household car ownership. Davis, CA: University of California Transportation Research Group Report UCD-TRG-RR-4.

Carmichael, B. (1993). Using conjoint modelling to measure tourist image and analyse ski resort choice. In P. Johnson \& B. Thomas (Eds.), Choice and demand in tourism (pp. 93-106). London: Mansell.

Chintagunta, P. K. (1992). Estimating a multinomial probit model of brand choice using the method of simulated moments. Marketing Science, 11, 386-407.

Chintagunta, P. K., \& Honore, B. E. (1996). Investigating the effects of marketing variables and unobserved heterogeneity in a multinomial probit model. International Journal of Research in Marketing, 13, 1-15.

Crompton, J. (1992). Structure of vacation destination choice sets. Annals of Tourism Research, 19, $420-434$.

Daganzo, C. F. (1979). Multinomial probit: The theory and its applications to demand forecasting. New York: Academic Press.

Dellaert, B., Ettema, D. \& Lindh, C. (1997). An activity-based framework for analyzing overnight long distance travel behavior. In D. Ettema \& H. Timmermans (Eds.), Activity based approaches to transportation modelling. In press.

Dey, A. (1985). Orthogonal fractional factorial designs. New Delhi, India: Wiley Eastern Limited.

Fesenmaier, D. (1995). A preliminary examination of the complex tourism decision making process. Working paper, University of Illinois at Urbana-Champaign, Department of Leisure Studies.

Gonul, F., \& Srinivasan, K. (1993). Modeling multiple sources of heterogeneity in multinomial logit models: Methodology and managerial implications. Marketing Science, 12, 304-317.

Gupta, S. (1988). Impact of sales promotions on when, what, and how much to buy. Journal of Marketing Research, 25, 341-355. 
Haider, W., \& Ewing, G. O. (1990). A model of tourist choices of hypothetical Caribbean destinations. Leisure Sciences, 12, 33-47.

Harlam, B., \& Lodish, L. (1995). Modeling consumers' choices of multiple items. Journal of Marketing Research, 32, 404-418.

Henderson, K. A., \& Bialeschki, M. D. (1991). The sense of entitlement to leisure as constraint and empowerment for women. Leisure Sciences, 13, 51-65.

Hooper, P. (1994). Evaluating strategies for packaging travel. Working Paper ITS-WP-94-4, Sydney, Australia: University of Sydney, Institute of Transport Studies.

Ingene, C. A., \& Ghosh, A. (1990). Consumer and producer behavior in a multipurpose shopping environment. Geographical Analysis, 22, 70-93.

Jackson, E. L. (1988). Leisure constraints: A survey of past research. Leisure Sciences, 10, 203-215.

Jansen-Verbeke, M. (1988). Leisure, recreation and tourism in inner cities: Explorative casestudies. Nederlandse geografische studies 58. Amsterdam/Nijmegen, the Netherlands: KNAG/ geografisch en planologisch instituut KUN.

Kahn, B. E., \& Lehman, D. R. (1991). Modeling choice among assortments. Journal of Retailing, 67, 274-299.

Kitamura, R. (1984). Incorporating trip chaining to analysis of destination choice. Transportation Research B, 18, 67-81.

Lieber, S. R., \& Fesenmaier, D. R. (1984). Modelling recreation choice: A case study of management alternatives in Chicago. Regional Studies, 18, 31-43.

Louviere, J. J., \& Timmermans, H. J. P. (1990). Stated preference and choice models applied to recreation research: A review. Leisure Sciences, 12, 9-32.

Louviere, J. J., \& Timmermans, H. J. P. (1992). Testing the external validity of hierarchical conjoint analysis models of recreational destination choice. Leisure Sciences, 14, 179-194.

Mansfeld, Y. (1992). From motivation to actual travel. Annals of Tourism Research, 19, 399-419.

McFadden, D. (1981). Econometric models of probabilistic choice. In C. Manski \& D. McFadden (Eds.), Structural analysis of discrete data (pp. 198-272). Cambridge, MA: MIT Press.

McFadden, D. (1989). A method of simulated moments for the estimation of discrete response models without numerical integration. Econometrica, 57, 995-1026.

Morey, E. R., Shaw, W. D., \& Rowe, R. D. (1991). A discrete-choice model of recreational participation, site choice, and activity valuation when complete trip data are not available. Journal of Environmental Economics and Management, 20, 181-201.

Oppewal, H., Louviere, J. J., \& Timmermans, H. J. P. (1994). Modeling hierarchical conjoint processes with integrated choice experiments. Journal of Marketing Research, 31, 92-105.

Peterson, G. L., Dwyer, J. F., \& Darragh, A. J. (1983). A behavioral urban recreation site choice model. Leisure Sciences, 6, 61-81.

Ryan; C. (1991). The UK package holiday industry. Tourism Management, 12, 76-77.

Sheldon, P. J. (1986); The tour operator industry: An analysis. Annals of Tourism Research, 13, 349-365.

Sheldon, P. J., \& Mak, J. (1987). The demand for package tours: A mode choice model. Journal of Travel Research, 25, 13-17.

Stynes, D. J., \& Peterson, G. L. (1984). A review of logit models with implications for modeling recreation choices. Journal of Leisure Research, 16, 295-310.

Swait, J. \& Louviere, J. J. (1993). The role of the scale parameter in the estimation and comparison of multinomial logit models. Journal of Marketing Research, 30, 305-314.

Theil, H. (1971). Principles of econometrics. New York: Wiley.

Williams, H. C. W. L. (1979). On the foundation of travel demand models and economic evaluation measures of user benefit. Environment and Planning A, 9, 285-344.

Woodside, A. G., \& Lysonski, S. (1989). A general model of traveler destination choice. Journal of Travel Research, 27, 8-14.

Woodside, A. G., Pearce, B., \& Wallo, M. (1989). Urban tourism: An analysis of visitors to New Orleans and competing cities. Journal of Travel Research, 28, 22-30. 